\title{
An Editor's Astrolabe
}

\section{Lloyd Free}

Few teachers and students of French would deny that a graduate review of French literature can be a valuable adjunct to higher education. But the paucity of French graduate reviews betrays a want of interest among faculty and lack of initiative among graduate students. To the benefit of the University of Kansas, the French Department has had both an enlightened faculty member, Professor Kenneth White who first suggested founding a graduate French journal, and resourceful students. Chimères was founded through the mutual cooperation of dedicated faculty members and a nucleus of students who had neither funds nor practical experience, but who took the initiative to found a literary journal. The reflections which follow are intended for equally enterprising students who would make a similar venture, and for faculty members who believe that a graduate program in French is more than classroom scholarship alone.

The graduate journal in its entirety, and even the printed page in its particulars, inevitably mirrors the basic policies of its editors. To be sure, it is no doubt possible to found a literary journal without serious forethought; but such a creation ex nihilo is distinctly inadvisable: the final product will reflect directionless editing, risk an ill-balanced layout, and worst of all will discourage a serious reading. It is essential, then, to define an editorial policy which will give direction to the general makeup of the review, before considering mechanics and problems of editing. The first object of the editors should be to respond to two primary questions: 1) to what audience is the review directed? 2) what is the function of the review in relation to this audience?

Our answer to the first question is firm, and explicitly stated on the credits page of every issue of Chi- 
mères: that the graduate review of French is written and published by graduate students of French and intended for graduate students of French. Implicitly, we assert thereby that our graduate student editors should be autonomous--free from faculty control and coercion--and that they may include anything they consider interesting and valuable to graduate students of French. But we also recognize that graduate students do not constitute an exclusive audience; indeed, we hope the review will also interest faculty and non-faculty, local and national. Thus we look continually to that resourceful editing which will find a middle ground, wherein the review will attract the graduate student and become a focal point of his interest, without excluding the general non-student audience.

A workable answer to the second question is necessarily more complex. Because of the varied and highly individual interests and education of its readers, the graduate review of French literature serves many ends: to please, interest, instruct and entertain; to provide hard found knowledge of editing and related problems to editors and contributors alike; to improve scholarship at the graduate level by providing motivation beyond the grade and classroom; to serve as an intellectual forum for students in a given university and a source of communication with students in other universities; to reflect the intellectual ethos of the French Department and the collective artistic talents of which it is composed. It is because the journal so represents the de-partment that we are concerned with its appeal and reception outside the department and the university.

These functions of the journal as we see them, as well as the audience as we have defined it, will shape the general policies and particular decisions of the editors. This prevailing editorial philosophy will effect every subsequent operation, from selection of materials for publication to format and layout. And the demanding and sometimes confusing task of keeping both the general and the particular in mind makes the editorial ideals vital to the journal's success. Those ideals are flexibility and variety.

Flexibility gives the editors the option of printing anything of literary or linguistic value that might in- 
terest students of French. Variety will sustain reader interest from cover to cover. Ideally a high standard of excellence should be the norm for publication, but variety must take precedence over excellence if excellence risks excluding original works in favor of serious scholarship. The editors must be ever vigilant to avoid the Scylla and Charybdis of 1) trivia, the scourge of the undergraduate journal and 2) reams of dul1 scholarship, the fagot of the professional literary review. Unlike the undergraduate review, the graduate magazine can honestly interest the established scholar: the neophyte critic can shed new light on matters of interest to the practiced one. Unlike the professional literary journal, whose audience is captive because it thinks of such readings as the obligatory business of its profession, the graduate review creates an interested audience through originality, variety, freshness of point of view, of style, of content. In sum, its editors are in the freest possible atmosphere for seeking out original work and for balancing and harmonizing scholarly research and original writing. This search for originality will extend even to the mechanics of the publication: format, art work, layout. Hopefully the end product will then constitute an esthetic whole and a true reflection of the student community's talents and interests.

But attention to what has been said so far will not necessarily see a first issue to print. If the end product is to be not only a first issue, but a growing, learning, and informing beyond it, the work does not stop here. Now comes the need for dedication and foresight, which can be exhausting and at times discouraging, but which is also compelling and real. Once editorial policy is determined, the founders of the graduate journal will still face four principal obstacles: apathy, time, money and inexperience. For these reasons, the role the first issue plays in perpetuating itself can hardly be overvalued. Student and faculty interest, particularly during the preparation of the first issue, is crucial. Student support is essential. Writing is hard and time-devouring work. Students may be induced or incited to contribute their efforts, but for the most part they will only do so voluntarily. Until 
the first issue is fact and the fruits of labor are clearly visible in print, most students will ignore even the efforts of the ideally enthusiastic editor and zealous staff. It is crucial, then, that faculty members patronize the journal from its inception. A far-sighted chairman and dedicated faculty members can help the student organizers immeasurably by recommending student research and creative materials which they judge suitable for publication. All things being normal, student interest will grow with each successive issue. The first issue, small and limited though it will probably be, will also have set a precedent, and with each new issue increasing numbers of students will enthusiastically submit scholarly and creative work. True growth can then begin: the standards of editorial selection can become increasingly discriminating.

A more difficult problem than student interest is one closely related to it--time. It is forever at a premium for graduate students, and the editors must make every effort to streamline publishing operations. Beware of an editorial structure that permits bickering, confusion and lost time. The object of all meetings and operations should be one practical result: the quickest, most efficient manner of getting the journal to press. The editor-in-chief will, of course, bear the principal burden of decision-making and coordinating operations. But he need not and should not take everything upon himself. He is both realistic and just if he distributes the work load by delegating major operations to the assistant editors.

Frustrating though the problems of interest and time may be, they are still secondary to finances, which are no doubt the major obstacle to finding and using student talent. Money is a factor over which students have no control, and struggling editors will probably have to grub for it. In fact, it will be difficult, if not impossible, to get money to print the first issue professionally. If necessary, mimeograph the first issue and do a linoleum block print on construction paper to serve as a cover. Go to press even if the format looks amateurish! It is essential to set a precedent, to produce something tangible at first, in order to bargain with it later. More enthusiastic departmental support, finan- 
cial and otherwise, will be forthcoming. With a copy of the first edition in hand, go to the chairman, the deans, the president of the university, the directors of outside social, fraternal, and civic organizations. Show them what you have done and propose what you would like to do: professional format and professional printing. But even then, do not ask for too much. Some professional printing processes can be overly demanding on the editor's time and energy and university budgets alike. You probably deserve some deaf ears, some nice smiles, and gentle pushes out of doors if you don't approach the printing problem with some workable compromises in mind. For example, Linotype is impractical for reasons of cost and time. Few Linotype setters know French, and the cost of Linotyping a foreign language is prohibitive. One type of printing seems best suited to the requirements of a graduate review. This is photooffset. Students who are fluent in French type the work to be published on bonded paper, within a given typing area to be photographed later by the printer. These typed pages are easily proofread and corrected by students. Art work can be drawn on the bonded paper or pasted on separate pages. Pages can be photographically reduced in size, a technique which permits the inclusion of lengthy bibliographies and like projects. The corrected photo-ready copy is then delivered to the printer who does the rest. This method of printing eliminates the high cost of setting type, problems of communication with a printer who does not know French, and the reading of galley proofs.

Lastly, a problem which can of ten be made less difficult than it might seem is student inexperience, which may discourage otherwise enthusiastic students. It is the editor's job to show them, primarily through example, that one learns by doing. The first issue of the journal may well contain some serious faults. But the second will contain fewer, as the publishing team learns what it must do to create a lively and interesting magazine. In fact, most publishing problems shrink to little or nothing when they are besieged with persistence and common sense. Common sense can be elusive; it is easy to miss or ignore. But one invaluable piece of common sense is to know where to solicit advice. Most 
universities have some kind of student or faculty publication, and those directing established publications are usually very willing to give advice if it is asked of them. The asking is a privilege which one should not hesitate to use, as often as he needs it. It might even be worthwhile to assign a continuing liaison with the university press as one of the duties of someone on the editorial staff.

But after all has been said and all possible helpful hints have been given, one looming consideration still remains: the essential thing is to begin, to have the fortitude to overcome the inherent obstacles, to improvise, to compromise, to exploit whatever immediate possibilities present themselves. All this is not an easy task. In fact, the beginnings of a graduate journal can be hard, and will demand much energy from the chosen few who are willing to give it. But once constituted, the well-directed graduate journal will quickly become a central adjunct to the advanced study of French language and literature.

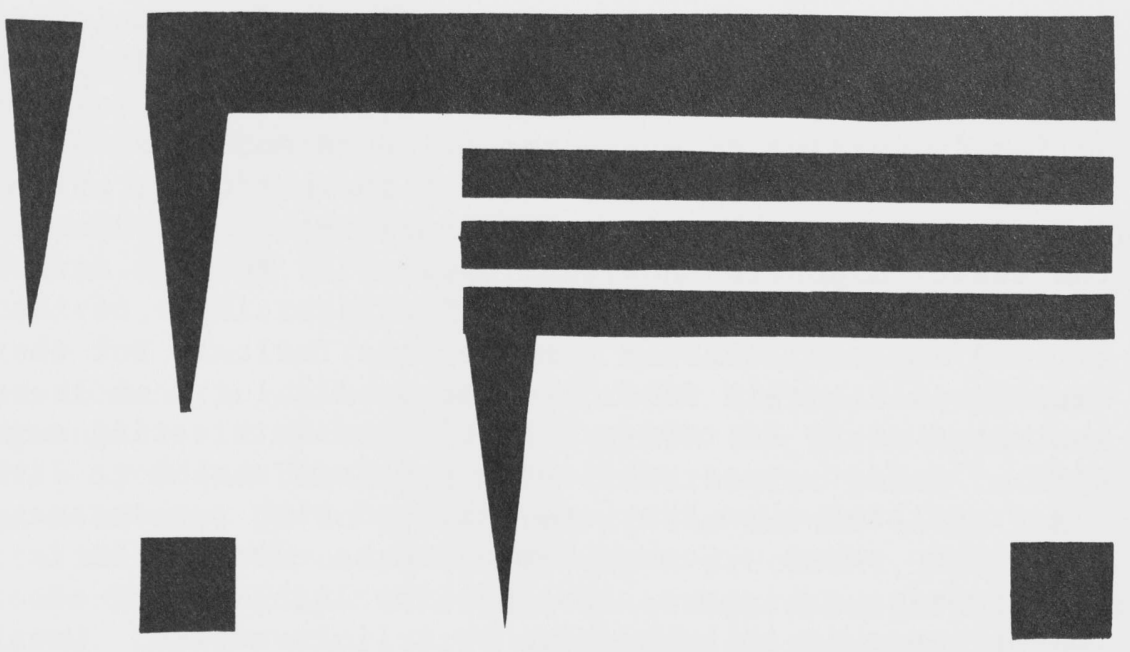

